\title{
Supporting the activities of curators who do not have a basic pedagogical education at $S$. Seifullin Agro Technical University
}

\author{
Almagul Zhussupova ${ }^{1,}$, Svetlana Shmachilina-Tsibenko ${ }^{2}$, Gulmira Suleimenova ${ }^{3}$, Dinara \\ Shakhmetova ${ }^{4}$, and Ainagul Yermekova ${ }^{5}$ \\ ${ }^{1}$ Pavlodar Pedagogical University, Mira str., 60, 140000 Pavlodar, Kazakhstan \\ ${ }^{2}$ Omsk Humanitarian Academy, 4th Chelyuskintsev st., 2 a, 644105 Omsk, Russia \\ ${ }^{3}$ Pavlodar Pedagogical University, Mira str., 60, 140000 Pavlodar, Kazakhstan \\ ${ }^{4}$ S.Seifullin Kazakh agrotechnical University, Zhenis avenue, 62, 010011 Nur-Sultan, Kazakhstan \\ ${ }^{5}$ Nazarbayev Intellectual School of Chemistry and Biology, Tkacheva, 16/2, 140000 Pavlodar, Ka- \\ zakhstan
}

\begin{abstract}
At present, the priority goal of the higher education system is the formation of a personality not only professionally competent, but also tolerant, capable of creativity, able to predict his role in a dynamic world, responsible and passionate. Actually, all these characteristics are set by the labor market for the training of qualified and competitive personnel. However, as scientific research and teaching practice show, not all students can independently achieve the necessary results due to their lack of adaptation to higher education. Therefore, we need specialists who can help them in this and show them the right direction. In this regard, there is a growing interest in the study of curatorial activity, its role and place in the higher education system. The article, within the framework of the "School of Curators" created at S. Seifulin Agro Technical University, analyzes the results of diagnostics in order to identify the pedagogical competence of curators, focuses on a number of reasons that impede their activities, as well as a number of tested areas of activity that contribute to their elimination, offers a number of measures aimed to improve the pedagogical culture of curators of student groups who do not have a basic pedagogical education.
\end{abstract}

\section{Introduction}

In modern conditions of modernization of education, its system in higher education remains the only social institution that translates and embodies the basic values and development goals of the modern society.

The educational activity of the university is an integral part of the educational process and is aimed on the formation of patriotism, citizenship, internationalism, high morality and ethics, legal culture, interfaith tolerance, as well as the development of versatile interests and abilities of students [1].

\footnotetext{
* Corresponding author: Alma1977@mail.ru
} 
The higher educational system is oriented towards the labor market and the training of qualified and competitive personnel. Possession of certain knowledge and skills within the framework of the chosen educational program (specialty), the desire for constant self-education, responsibility and hard work of the student are able to ensure his successful professional development in the future. In this regard, the role of higher educational institutions is increasing, regardless of their direction (technical, pedagogical, humanitarian-economic, etc.) in the education of a student as a future specialist.

A curator of academic groups plays a significant role in educational work with the students at the university. He is one of the key links in the educational system of the university, is in direct close contact with the students, like no one else, knows everything about the student group that he supervises [2]. The curator is the link between the administration, teachers and students [3].

Studying world scientific publications and reviewing literary sources on this issue, we noticed that the image of the curator is considered in them to a greater extent as a person working in the field of art. Curatorial work is at the intersection of cultural and political spheres. Curatorial activity in the field of education is not considered at the proper level. Foreign researchers, as a rule, synonymize curatorial and tutoring activities $[4,5,6]$.

A number of Russian researchers, in particular I.S. Shapovalova and I. A. Sharshov [7, 8] position supervision from the point of view of organizing educational work in a group, managing the formation of a student collective. Others, for example E. Ya. Belskaya and O. N. Igna [9] consider the institution of supervision as a necessary component of an integral educational and educational space.

T.P. Bugaeva, in her research work, considers the problem of identifying pedagogical conditions for increasing the effectiveness of the educational system of a modern university with the dominant role of curatorial activity. As a result, it was proved that the pedagogical conditions for the implementation of curatorial activities contribute to an increase in the effectiveness of the educational system of the university [10].

A. V. Kuprina, in turn, notes that "the institution of curators is a key structure in the system of educational work of the university, which implements a program for teaching students through the formation of an active social position, civic consciousness, the development of general culture and professional and labor skills" [11, p . 40]. With which it is difficult to disagree.

L. N. Zainullina in her scientific work indicates an insufficient amount of research on the system of carrying out curatorial activities. This can be clearly seen in the contradiction presented by the author between "the multifunctionality of the educational activities of the curators of student groups and the lack of a clear definition of the main directions in which their educational activities should be carried out" [12].

However, today a rather significant problem comes to the fore, which has not yet been considered, concerning the preparation of specialists for curatorial activities without basic pedagogical education, their pedagogical support in the development of important targets and aspects of educational activities in non-pedagogical universities.

Now in modern universities, in particular in agricultural, there is an awareness of the need to intensify educational activities, search for new forms of work with students, develop a legal framework for the activities of curators, their methodological support and interaction with students. The inconsistency of the current situation is manifested in the fact that a significant part of teachers do not feel the need to perform the functions of a curator, since it is an additional social load or simply cannot at a productive level solve those educational tasks that the curator of academic groups should solve.

The situation in non-pedagogical universities with regard to the quality of curatorial activities is complicated by the fact that the curator's readiness for self-improvement and selfeducation in the field of pedagogy and psychology is determined by the curator himself, and 
the improvement of his psychological and pedagogical literacy, the provision of social and psychological assistance to him depends on how organized the university system functions, as well as the interest of the administration in it.

\section{Objectives and methodology}

The purpose of this work is to analyze the experience of organizing pedagogical support for curators of student groups who do not have basic pedagogical education in an agricultural university of the Republic of Kazakhstan.

The educational process in our agro-technical university is implemented by both curators who have received a special pedagogical education and curators who do not have it. The category of curators who do not have a special pedagogical education include curators-teachers who were selected from among the graduates for working at the department, or invited practicing specialists in their field (production workers, practicing economists, lawyers, etc.). The experience of such involvement in curatorial activities is practiced in a number of universities in Kazakhstan, as well as in S. Seifullin Kazakh Agrotechnical University.

However, such specialists experience certain difficulties in carrying out curatorial activities, since they do not have basic pedagogical education, and, therefore, do not have basic pedagogical competencies. They do not have experience of working with students of different ages, do not have an adequate level of knowledge about the psychological, pedagogical and age characteristics of student youth, the peculiarities of the theory and methodology of educational work at the university, do not have a clear idea of the activities of the student group curator, its mission and purpose.

\section{Discussion of research results}

To resolve this problem, in 2015, S. Seifullin Kazakh Agro Technical University organized a "School of Curators" and developed a regulation on its activities. The regulation on the school of curators was developed by the department for educational work together with the quality service and approved by the order of the chairman of the board of the NAO University. The position presents the main goals, objectives and directions of the school of curators, planning its work, the fundamental functions of curators, accounting and reporting of the work of the school of curators, etc.

The main goal of the school of curators is to improve the scientific and methodological level of training of curators in psychological and pedagogical issues, improve the quality of educational and scientific activities of students, create a favorable socio-psychological climate in the study group by teachers-curators, increase the intellectual and moral level of students.

Functions of the school of curators of S. Seifulin Agro Technical University:

- coordination of educational activities of curators;

- study and generalization of the best experience of the leading curators in all areas of educational work (civil-patriotic, moral, aesthetic, environmental education, etc.), as well as the study of the experience of educational work with students in other universities of the city and country, and its implementation into practice university;

- organizing and conducting a lecture hall on the development of modern education technologies by curators (forms, means and methods of educational work);

- organization of courses and training seminars (trainings) for the curators of the university to provide students with psychological support;

- preparation and publication of educational and methodological recommendations for the education of students and the organization of the work of curators; 
- organization of conferences, round tables and other forms of exchange of experience in order to develop proposals for improving the content, forms and methods of educational work in higher educational institutions of the Republic of Kazakhstan;

- assists in the work of novice curators.

In this regard, the following areas of work of the School of Curators were selected as priorities:

- organizing and conducting interactive classes, master classes, projects, moderation technologies aimed at studying and mastering the essence of the educational process at a university, the specifics of using methods, means and forms of educational work;

- coordination of group and individual consultations in the offline and online mode, psychological and pedagogical trainings with the involvement of relevant specialists;

- modeling of training exercises and tasks for the preparation of psychological-pedagogical and educational-methodological documentation for working with students;

- designing and holding events (round tables, problem seminars, conferences, workshops) on various aspects of education, youth policy, social, pedagogical and psychological support for students;

- carrying out monitoring work for the purpose of researching problems in educational work and curatorial activities;

The university is interested in the effectiveness of the curators' work, and therefore in every possible way supports the functioning of the "School" by providing various kinds of support.

For example, to identify the problems faced by curators who do not have a pedagogical education and to build a plan for further work with them, the school of curators, together with the teachers and psychologists of the university, prepared and tested curators.

First of all, it was necessary to get to know the teacher-curator himself, to build his "portrait" as a teacher-educator. At the same time, we used the methodology of G.V. Rezapkina "Psychological portrait of a teacher", which allowed us to see the psychological reasons for professional difficulties in curatorial activities [13].

The methodology was developed on the basis of an analysis of research in the field of professional competence of teachers and the study of the personal characteristics of a teacherteacher. The author of the methodology claims that the psychological, emotional state of the student, his adaptation and further both educational and educational activities completely depend on the teacher-teacher. The teacher must be satisfied with his work, interested in the positive result of his work, and most importantly, have the ability and professional competence in communicating with students. As a result of testing, a complete psycho-logical portrait of the teacher emerges, in which he can see the areas in which correction and work on competencies is necessary. And some teachers, curators, the test result will make them think about the correct choice of profession [14].

The focus of this methodology is based on identifying important pedagogical competencies of the teacher-curator: his priority values; psycho-emotional state; self-esteem; parenting style; the level of subjective control.

The testing took place online on the website of the University's School of Curators, which gave us the opportunity to test 270 curators, which made it possible to see not only the focus of curators, but also the difficulties that each curator faces individually, as well as identify the problems in general.

At the end of the testing, based on the analysis of the answers of the teacher-curators, we obtained the following results:

$36 \%$ (98 people) teachers-curators share the interests of students, their problems. In addition, for $27 \%$ ( 74 people), the support of colleagues, their recognition is important, which is essential in the curatorial activity. However, $36 \%$ (98 people) of curators believe that besides work, there are other values and opportunities for self-realization. 
The results of the method showed a generally stable psycho-emotional state of the curators. Although, the comparative analysis of the answers is somewhat contradictory. So, for example, only $9 \%$ (23 people) answered that working at a university takes a lot of physical and mental strength, while $42 \%$ (112 people) have an increased sensitivity of the nervous system, and 50\% (135 people) a safe psycho-emotional state.

The results of the analysis of the scale "Self-esteem", testifies to the positive self-perception of the world and reality 38\% (102 people), at the same time $32 \%$ ( 85 people) instability of self-esteem and its dependence on external circumstances, mood and opinions of others. The need to carry out a lot of work on the development of the communicative qualities of curators is evidenced by the answers about the ease of entering into free communication with others $31 \%$ ( 83 people)

The position of the leader in the team is close $35 \%$ ( 95 people) of curators; the position of a peacemaker is inherent in $57 \%$ (155 people). However, only $8 \%$ (20 people) of $100 \%$ (270 people) of student supervisors recognize the student as an equal partner, which indicates a low level of their communicative competence.

Diagnostics of the level of subjective control showed the following results. Only 29\% (77 people) are inclined to take responsibility for everything that happens in life, are active and confident in themselves. While 35\% (93 people) are not sufficiently responsible for the existing relationships and the circumstances of their life. $37 \%$ (100 people) are inclined to attribute responsibility for the events of their lives to other people, to chance, fate, more than others are subject to the phenomenon of "combustion ".

Interpreting the answers of the curators on the scale of "priority values of the teacher", we note that 49 curators out of $98(50 \%)$ were young specialist teachers working at the university for 1 to 3 years, the next $50 \%$ of the curators are teachers, curators with more than 10 years of experience. The same number of curators ( 98 people) chose two options on the same scale. In this case, it can be interpreted in two meanings, firstly: the behavioral attitudes of the curators may fluctuate, they are not yet formed; secondly: a variety of behavioral stereotypes.

The technique we have carried out gives us the opportunity to identify the reasons for the professional difficulties of the curators of student groups. Based on the test results, we see the strengths and weaknesses in the behavior of curators. Considering the strong (positive) side of the curators' behavior, a great number of curators (135 people) have a favorable psycho-emotional state, 102 curators have a positive self-esteem. These curators are emotionally stable, can positively influence the psychological climate in the group, easily create an atmosphere of live communication and provide psychological support to students . The analysis of the results of testing teacher-curators according to five indicative scales of this methodology is presented in the table 1 .

Table 1. Analysis of indicators of psychological causes of professional difficulties of teacher-curators

\begin{tabular}{|l|l|l|l|l|l|}
\hline $\begin{array}{l}\text { Scal } \\
\mathrm{e}\end{array}$ & $\begin{array}{l}\text { Priority } \\
\text { values of } \\
\text { the } \\
\text { teacher- } \\
\text { curator }\end{array}$ & $\begin{array}{l}\text { Psycho- } \\
\text { emotional } \\
\text { state }\end{array}$ & Self-esteem & $\begin{array}{l}\text { Parenting } \\
\text { style }\end{array}$ & $\begin{array}{l}\text { The level of subjec- } \\
\text { tive control }\end{array}$ \\
\hline
\end{tabular}




\begin{tabular}{|c|c|c|c|c|c|c|c|c|c|c|c|c|c|c|c|}
\hline & 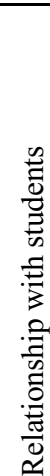 & 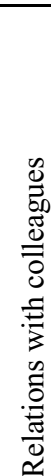 & $\begin{array}{l}\text { d } \\
0 \\
.0 \\
.0 \\
0 \\
0 \\
0 \\
0 \\
0\end{array}$ & 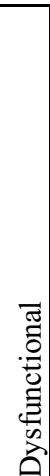 & 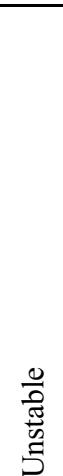 & 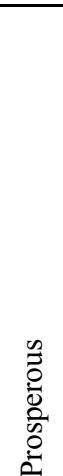 & $: \stackrel{0}{:}$ & $\frac{0}{\frac{\pi}{0}} \frac{0}{0}$ & 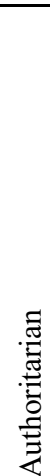 & 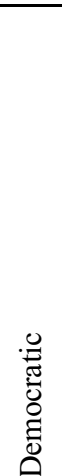 & $\begin{array}{l}\bar{\pi} \\
\overline{0} \\
: 3\end{array}$ & 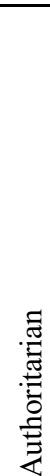 & 氙 & $\begin{array}{l}\overrightarrow{\mathscr{U}} \\
\mathbb{\Xi} \\
\stackrel{0}{0}\end{array}$ & 3 \\
\hline $\begin{array}{l}\text { Indi } \\
\text { cato } \\
\text { rs } \\
\text { on } \\
\text { scal } \\
\text { es }\end{array}$ & $\begin{array}{l}36 \\
\%\end{array}$ & $\begin{array}{l}27 \\
\%\end{array}$ & $\begin{array}{l}36 \\
\%\end{array}$ & $\begin{array}{l}9 \\
\%\end{array}$ & $\begin{array}{l}42 \\
\%\end{array}$ & $\begin{array}{l}50 \\
\%\end{array}$ & $\begin{array}{l}38 \\
\%\end{array}$ & $\begin{array}{l}32 \\
\%\end{array}$ & $\begin{array}{l}31 \\
\%\end{array}$ & $\begin{array}{l}35 \\
\%\end{array}$ & $\begin{array}{l}57 \\
\%\end{array}$ & $\begin{array}{l}8 \\
\%\end{array}$ & $\begin{array}{l}29 \\
\%\end{array}$ & $\begin{array}{l}35 \\
\%\end{array}$ & $\begin{array}{l}37 \\
\%\end{array}$ \\
\hline
\end{tabular}

In addition, we were able to see the weak and negative aspects of behavior, the peculiarities of the nervous system of the curators. For example, 112 curators had an unstable psycho emotional state, the cause of which may be congenital hypersensitivity of the nervous system, an unfavorable combination of circumstances, as well as personal characteristics. 155 curators use a liberal (conniving) style, which is unacceptable when working with the students. The organization and control of students' activities is haphazard, contact with the students is lost, and subsequently the authority of the curator has no effect on students. The responses of 100 curators showed us that they have a low level of subjective control, i.e. these curators are not ready to take responsibility of any kind, they are inclined to ascribe responsibility for various events in their lives to other people, chance. It will be difficult for a curator with a low level of responsibility to carry out curatorial activities, since responsibility is one of the characteristic features of a person who determines a full-fledged personality. In the educational work of the curator, students are the object of responsibility.

The methodology helped to identify the problems of the psychological and pedagogical nature of the curator himself, and further work was built primarily in conjunction with university psychologists. The work plan of the school of curators was developed taking into account the coordination and improvement of the activities of the curator, each planned event was discussed and corrected by experienced teachers and psychologists. There was a need to choose new forms and methods of working with curators to improve their professional psychological and pedagogical competence.

In order to identify the attitude of students to the importance of the activities of curators, the need for their functioning, the practice of selecting the composition of curators, an annual survey is conducted.

Such data were obtained as a result of questioning 1044 students from various faculties (agronomic, technical, energy, economic, faculty of veterinary medicine and animal husbandry technology, faculty of computer systems and vocational education, faculty of land management, architecture and design). The survey was anonymous and included 6 openended questions.

Analyzing the answers of students, one can identify the main points of the results of the questionnaire.

Summing up the percentages of positive results on the first question "How often do you meet with the group?" $47 \%$ of students see the curator once a week, exclusively during the curatorial hour; $39 \%$ - several times a week; $10 \%$ - almost every day to control the situation of the group. Thus, it can be noted that the majority of students $(96 \%)$ answered that curatorial hours are conducted by curators in accordance with the plan of educational work, and interaction with the group curator is carried out in a normal mode. 
To the next question regarding the conduct of curatorial hours - in general, students are satisfied with the quality of their curator's work ( $48 \%$ of students - interesting topics are discussed; $26 \%$ - assignments of the dean's office are being completed; $17 \%$ - conversations with problem students are held). They note that the curator's hour is the time specially allotted to the curator for carrying out educational work with the group. And also $2 \%$ of students gave negative indicators in the answers, which were associated with the subjective assessment of the student (example of a free answer: I was once, but I don't remember what happened; in tension and fear for me personally.)

To the question "Does the curator know about your problems?" (this question implies problems of a different nature) students answer that curators are more interested in the educational activities of students, their academic performance $(82 \%)$, and to a lesser extent $(19 \%)$ are interested in their personal and family problems.

$98 \%$ of students show great interest in curatorial hours on the functioning of the educational process, design of free time and employment, as well as in the organization of psychological trainings, pedagogical role-playing and business games aimed at solving problems of an individual and collective nature. It should be noted that $2 \%$ of students, which mostly include graduate students, do not see a great need for curatorial hours and offer to hold meetings with curators in an informal setting, and there are also proposals to remove the curatorial hours altogether.

According to the results of the question "Does the curator keep in touch with the parents?", students (76\%) see the relationship of the curator with the parents only when it is necessary when it comes to academic performance or student discipline violations, etc., only $24 \%$ of students, in their answers claim that the curator does not keep in touch with the parents.

The final question of the questionnaire is aimed at putting forward proposals for improving the work of the curator at the university. As suggestions for improving the curatorial work at the university, $90 \%$ of students suggest conducting curatorial hours, where they celebrate the achievements of the group and the possibility of choosing topics of curatorial hours that are interesting for students. Most of the students who gave proposals for curatorial work were students of 1,2, 3 courses. The rest of the students (10\%), which included students of graduate groups ( 3 courses of the abbreviated form of study and the 4th course), give different proposals, among which there are both positive and negative opinions. For example, curators are not needed, just as curatorial hours are not needed.

The conducted research identified "painful" points in the activities of curators and their interaction with students and allowed us to identify areas for further improvement of their work:

It was aimed at the implementation of psychological and pedagogical support for the activities of curators, improving the quality and efficiency of the methodological and organizational components of educational work with students, improving their personal growth and psychological and pedagogical competence, ensuring the organization and coordination of their effective activities, in particular, as priority directions of psychological and pedagogical diagnostics were identified, where the curator, together with the psychologist, must learn to master the tools for studying the individual characteristics of the students of the group, using the analysis of documentation, interviewing students, questioning, etc .; development of the level of the pedagogical culture of the curator, its structural components.

In this regard, within the framework of the "School of Curators", a scientific and methodological seminar "Educational environment of the university: traditions and innovations" was held. The seminar was organized with the aim of providing various ways to improve the professional psychological and pedagogical competence of teachers, curators; improving the quality and efficiency of work with students of academic groups; monitoring the quality of curatorial activities at the university. 
This goal involves solving the following tasks:

1. Formation of professional and necessary orientations of curators in the implementation of ideological and educational work with student youth.

2. Increasing the level of professional competence of curators as a set of semantic orientations, knowledge, skills and experience of curators' activities in relation to a certain pedagogical reality, necessary for the implementation of personally and socially significant professional curatorial activities.

3. Creation of conditions for effective personal and professional promotion of the seminar participants as curators of the student group, the development of their pedagogical abilities and creative potential.

4. Expansion of experience in the effective resolution of professional, social and personal problems in the process of carrying out curatorial activities.

The moderators of the seminar were educators of the Republic of Kazakhstan, doctors of pedagogical and psychological sciences, practicing psychologists together with the president of the Association of Practical Psychologists Nur-Sultan and others. They shared their experience of work with student youth, made presentations revealing the deontological aspect of teaching. An important emphasis in all speeches was placed on educational work at the university and the criteria for its productivity, technological procedures for training curators with the current level of pedagogical culture.

The practical part of the seminar within the work of the sections was organized based on the results of the diagnostics obtained and the needs of the curators.

All sections were held in the form of Master Class, carried a practical focus, both professionally and personally. As, for example, prevention of emotional burnout syndrome, techniques and techniques for increasing stress resistance of a curator, overcoming conflict situations in a student group, tolerance in a student environment, training technologies in the formation of a collaborative group environment, familiarity with psychological tests for selection (for vacancies, personnel reserve, professional suitability, psychogram), etc.

In conclusion, I would like to note that the School of Curators (Institute of Curatorship) plays a huge role in the educational system of higher education. The school of curators helps, supports and accompanies the work of curators for their further improvement in professional, psychological and pedagogical competence in working with a student group, as well as in striving for self-development, self-actualization and creative self-realization in the teaching profession and educational activities

\section{Conclusion}

Based on the above, we can conclude that the students of S.Seifullin Kazakh Agrotechnical University are interested in interacting with curators, while noting the expansion of their functional duties and role functions. The current generation of students, especially first-year students, need not only curatorial hours, where they are mainly busy discussing educational issues, but also social support, moral, spiritual and personal development.

When organizing the process of improving the activities of the curator, the School of Curators should take into account the following recommendations:

- clear definition of the boundaries of official duties and powers of curators;

- further work of the school of young curators;

- publication of guidelines for curators;

- organizing internships, passing refresher courses in other universities, in universities in other cities for the exchange of experience;

- patronage over the curators of departments of non-pedagogical direction;

- encouraging the work of curators;

- regular psychological trainings, games, exercises, etc. 
- conducting competitions for the best curator.

Students want to see in their curator a person who can help adapt to university requirements and build interpersonal relationships in a group; motivated to provide pedagogical support in a difficult life situation; able to guide them in their professional activities, as well as possessing the skills to develop the qualities necessary for a competitive personality.

Meanwhile, the analysis of the diagnostics carried out, as well as the work carried out with the curators of student groups indicate the need to continue systematic pedagogical work on pedagogical support of curators, to increase their pedagogical competence and improve pedagogical culture. Actually, without these components, it is impossible to achieve high performance in the work of student curators.

\section{References}

1. N. S. Beilina, Educational activities of the student group curator on the formation of general cultural and professional competencies, Bulletin of the Samara State Technical University. Series: Psychological and pedagogical sciences 2(26),10-18 (2015)

2. I. F. Isaev, Higher school pedagogy: supervising a student group: a textbook for universities. Higher education, 365 (Moscow: Yurayt Publishing House, 2020)

3. E. N. Krolevetskaya, The role of the curator in the professional education of future teachers, Extracurricular work as a means of increasing the practical orientation in the training of primary education specialists: Materials of the interuniversity scientificpractical conference, 29-31 (Belgorod: Publishing house BelRIPKPPS, 2017)

4. M.A. Gorshkova, To the question the role of the curator in the university educational space. Central Russian Journal of Social Sciences 10(3), 241 - 246 (2015)

5. M.A. Gorshkova, Model of the educational activities of the curator of the student group at the pedagogical University, 27 (Moscow, 2011).

6. E. Ya. Belskaya, O. N. Igna, The curatorship institute role in modern higher professional education. Bulletin of Tomsk State Pedagogical University (TSPUBulletin) 12(189) (2017)

7. A. V. Sereda, G. Yu. Titova, Curatorial activity as a means of developing the professional competence of students of a pedagogical university, Scientific and pedagogical review (Pedagogical Review) 2(12), 84-91 (2016)

8. I. A. Sharshov, The criterion apparatus for assessing the professional education of students in the context of student self-government at the university, Personal and professional development of the future specialist, 405-413 (Tambov, 2016)

9. E. Ya. Belskaya, O. N. Igna, The role of the institution of supervision in modern higher professional education, Bulletin of the Tomsk State Pedagogical University 12(189), 1315 (2017)

10. T.P. Bugaeva, Curator's activities in a modern university: author. dis. ... Cand. ped. Sciences, 26 (Novokuznetsk, 2010)

11. S. P. Akutina, T. T. Shchelina, Modern models of supervision in higher education, Bulletin of Nizhny Novgorod University named after N.I. Lobachevsky. Series: Social Sciences, 1(41), 34-35 (2016)

12. L. N. Zainullina, The main directions of the educational activities of the student group curator, Engineering Bulletin of the Don 1(24), 23 (2017)

13. G. V. Rezapkina, Development of the teacher's professional self-awareness. Bulletin of Practical Psychology of Education 8(1), 105-118 (2011) 
14. A. Z. Minakhmetova, Psychodiagnostic component of teacher's professional activity, Concept 01, ART 13506, 5 (2013)

15. E.B. Shmakova, The role of the curator in the educational and educational activities of the university, Problems of modern science and education 11(41), 179-182 (2015)

16. D.U. Sobirova, A.T. Azimov, D.K. Alimova, The role of the curator in higher Education university. European Journal of Research and Reflection in Educational Sciences, UK. 7(3), 76 (2019) 